\title{
Modification of borosilicate glass composition for joint thermal processing with lead oxide glasses for development of photonic crystal fibers
}

\author{
Jarosław Cimek • Ryszard Stẹpień • Mariusz Klimczak • Ireneusz Kujawa • \\ Dariusz Pysz • Ryszard Buczyński
}

Received: 15 January 2014 / Accepted: 20 August 2014 / Published online: 7 September 2014

(C) The Author(s) 2014. This article is published with open access at Springerlink.com

\begin{abstract}
Development of photonic crystal fibers made of two or more types of glasses can be of considerable advantage in designing of specific properties of photonic crystal fibers. Replacing air holes with a medium with different refractive index provides an additional degree of freedom in fiber dispersion designing. Multi-component oxide glasses can be easily modified by changing the concentration of its ingredients, which in turn changes thermomechanical and optical properties of glass. In this paper, we discuss feasibility of joint thermal processing of two types of glasses for photonic crystal fiber drawing. Specifically, we optimize composition of our in-house synthesized high-alkaline borosilicate glass. A series of sixand seven-component glasses synthesized in $\mathrm{SiO}_{2}-\mathrm{B}_{2} \mathrm{O}_{3}-\mathrm{Al}_{2} \mathrm{O}_{3}-(\mathrm{BaO})-\mathrm{Li}_{2} \mathrm{O}-\mathrm{Na}_{2} \mathrm{O}-\mathrm{K}_{2} \mathrm{O}$ oxide system was examined in experiments of combining with commercial lead-silicate glasses F2 and SF6. Joint thermal processing was validated by demonstration of successfully drawn structures of all-solid glass photonic crystal fibers. Critical glass parameters for thermal process of preform fabrication and subsequent fiber drawing, such as thermal expansion coefficient, characteristic viscosity temperatures and crystallization susceptibility were measured, and matched to F2 and SF6 glasses by optimizing composition of borosilicate glasses.
\end{abstract}

Keywords Soft glass · Glass thermal processing · Photonic crystal fibers · Group refractive index

\section{Introduction}

Multi-component silicon oxide based glasses have become of considerable interest due to their various properties and possibility to modify them by adjustment of composition. Large

J. Cimek · R. Stępień · M. Klimczak · I. Kujawa · D. Pysz · R. Buczyński ( $₫)$ Institute of Electronic Materials Technology, Wólczyńska 133, 01-919 Warsaw, Poland e-mail: rbuczyns@igf.fuw.edu.pl

J. Cimek · R. Buczyński

Faculty of Physics, University of Warsaw, Pasteura 7, 02-093 Warsaw, Poland 
number of possible compositions enabling fiber drawing, make this type of glasses attractive to investigate in context of fiber optics technology and other optical applications.

Adjusting of glass properties by composition change enables possibility to match two different glasses for joint thermal processing. All-solid photonic crystal fibers, in which glass rods take place of air holes in the photonic structure, first shown by (Feng et al. 2003) find applications in supercontinuum generation (Pniewski et al. 2013), sensing (Gu et al. 2011), and lasing (Olausson et al. 2008). Notably, chalcogenide glasses have also been used in all-solid glass photonic crystal fiber drawing (Toupin et al. 2013).

Photonic crystal fibers (PCF) drawn from a single type of glass and comprising a lattice of air-holes offer a degree of freedom in fiber designing, which is limited by properties of the single used glass. Fabricating PCF fibers with lattice composed of a different type of glass instead of air, broadens PCF design freedom, regarding to possibility to modify the refractive index contrast between two glasses. (Buczynski et al. 2012). In case of photonic crystal fibers made of one glass and air holes, the difference in refractive index is determined only by chromatic dispersion of glass. In all-solid photonic crystal fibers this contrast is determined by difference between the dispersion of refractive indices of the two used glasses. This results in possibility of tuning the modal and dispersion properties, which constitutes the additional degree of freedom in fiber designing. Additionally, joining two types of glasses enables other advantages, like matching glasses with different spectral transmission ranges or easier formation of nanostructured fibers, which is impossible with just an air-hole based photonic lattice. Choosing fused silica as the main material for all-solid PCF fiber enables to obtain attenuation below $20 \mathrm{~dB} / \mathrm{km}$ around 1,550nm (Bouwmans et al. 2005). Also long period gratings in this type of fibers has been reported (Jin et al. 2008). One of the highest degrees of miniaturization in a fiber-optics based optical component fabricated from jointly synthesized and drawn glasses is the nanostructured gradient lens, which includes sub-wavelength structures to shape an incident beam, and can serve e.g. as an output collimator glued directly to an optical fiber's facet (Nowosielski et al. 2012). Additionally the need of low index glass family for fabricating dual glass structures like birefringent materials (Waddie et al. 2011), with high index glasses (Stępień et al. 2013), offer wide possibility to fabricate structures with high index contrast between them.

High-alkaline borosilicate glasses are relatively easy to synthesize-their melting, homogenizing and clarifying temperatures rarely exceed $1300^{\circ} \mathrm{C}$. Homogenous material with very good optical quality can be obtained by use of conventional melt-quenching technique, without applying special melting conditions like protective atmosphere.

The glasses of this type are optical materials which thermal and optical properties, such as viscosity, thermal expansion, refractive index, can be easily modified in a broadband range through the concentration changes of the whole glass components. This way the properties of the newly developed borosilicate glass can be matched to the properties of the commercially available lead-silicate glasses, such as Schott's F2 and SF6, to enable joint thermal processing into photonic fibers and microstructured optical elements.

When considering matching of glass properties for joint thermal processing (i.e. fabrication of fiber optic components at a fiber drawing tower), critical parameters adjusted in the first place are those describing thermo-mechanical and crystallization properties while optical properties, like transmission and refractive index, are usually considered in the second place.

In this work we investigate modification of borosilicate glass properties by variation of composition, in order to allow joint thermal processing with commercial Schott's F2 or SF6 lead-silicate glass for photonic crystal fiber fabrication. The goal of the study was to 
Table 1 Chemical composition of the synthesized high-alkaline borosilicate glasses

\begin{tabular}{|c|c|c|c|c|c|c|c|c|c|c|}
\hline \multirow[t]{3}{*}{ Oxide } & \multicolumn{10}{|c|}{ Glass code } \\
\hline & \multicolumn{2}{|l|}{$\mathrm{NC}-17$} & \multicolumn{2}{|l|}{ NC-18 } & \multicolumn{2}{|l|}{ NC-19 } & \multicolumn{2}{|l|}{ NC-20 } & \multicolumn{2}{|l|}{$\mathrm{NC}-21 \mathrm{~A}$} \\
\hline & {$[\% \mathrm{~mol}]$} & [\%mas] & {$[\% \mathrm{~mol}]$} & [\%mas] & [\% mol] & [\%mas] & {$[\% \mathrm{~mol}]$} & [\%mas] & {$[\% \mathrm{~mol}]$} & [\%mas] \\
\hline $\mathrm{SiO}_{2}$ & 54.99 & 49.41 & 56.00 & 51.44 & 55.94 & 51.44 & 56.60 & 54.46 & 56.84 & 55.00 \\
\hline $\mathrm{B}_{2} \mathrm{O}_{3}$ & 22.00 & 22.91 & 22.00 & 23.42 & 22.79 & 24.29 & 23.08 & 25.74 & 23.19 & 26.00 \\
\hline $\mathrm{Al}_{2} \mathrm{O}_{3}$ & 0.61 & 0.93 & 0.61 & 0.95 & 0.61 & 0.95 & 0.61 & 0.99 & 0.61 & 1.00 \\
\hline $\mathrm{BaO}$ & 4.90 & 11.24 & 3.00 & 7.04 & 3.19 & 7.50 & 0.41 & 0.99 & - & - \\
\hline $\mathrm{Li}_{2} \mathrm{O}$ & 5.01 & 2.24 & 5.00 & 2.29 & 5.00 & 2.29 & 6.20 & 2.97 & 6.23 & 3.00 \\
\hline $\mathrm{Na}_{2} \mathrm{O}$ & 9.00 & 8.35 & 9.00 & 8.53 & 8.99 & 8.53 & 9.48 & 9.41 & 9.51 & 9.50 \\
\hline $\mathrm{K}_{2} \mathrm{O}$ & 3.50 & 4.92 & 4.40 & 6.33 & 3.47 & 5.00 & 3.62 & 3.63 & 3.63 & 5.50 \\
\hline
\end{tabular}

experimentally validate optimization of glass composition, which would enable fabrication of all-solid PCF and such a fiber, drawn as a proof- of -concept is presented.

\section{Optimization of glass composition}

\subsection{Glass synthesis}

Compositions of glasses are designed to obtained thermo-mechanical and rheological properties similar to commercial Schott's F2 and SF6 lead-silicate glasses. Initial compositions of glasses labeled NC-xx are shown in Table 1. All raw materials used for glass melting, grinded quartz glass and other chemicals, had a purity of $99.9 \%$. Designed compositions of substrates were melted in a resistance furnace, in a corundum crucible. This type of glass is not chemically aggressive, and did not damage the crucible made of alumina oxide. Despite this, after several melting processes, an etched ring in the inner side of the crucible could be clearly seen. These phenomena had to be taken into account in the considerations of real glass composition after melting. The melted glass, after pouring into preheated graphite mould, was $2 \mathrm{~h}$ thermal treated at $510^{\circ} \mathrm{C}$ and then annealed by slowly cooling at a rate of $0.5 \% \mathrm{~min}$. Overall process was performed in the Glass Department at Institute of Electronic Materials Technology (ITME).

\subsection{Characterization of glass}

A dilatometer 801 type of Baehr Thermoanalyse $\mathrm{GmbH}$ was used to measure linear thermal expansion coefficient. Four characteristic glass temperatures-lower annealing point, transition temperature, upper annealing temperature, and dilatometric softening point - related to the dynamic viscosity $\eta=10^{14.6} ; 10^{13.4} ; 10^{13}$ and $10^{11} \mathrm{P}$ (Poise) were determined based on the obtained thermal expansion curves. The further specific glass temperatures were obtained with a Leitz heat microscope. A cube-shaped sample with dimensions $4 \times 4 \times 4 \mathrm{~mm}^{3}$ was inserted into a furnace and the shape of the sample was observed. At characteristic viscosities, glass changes its shape from cubic to oval $(\log \eta=9.0)$, sphere $(\log \eta=6)$, hemisphere $(\log \eta=4)$, and at very low viscosity $(\log \eta=2)$ the glass spreads. The final viscosity curves $\left(\log (\right.$ Viscosity $[\mathrm{P}])$ vs. temperature $\left.\left[{ }^{\circ} \mathrm{C}\right]\right)$ were determined based on the measurements in the dilatometer and in the heat microscope. 
(a)

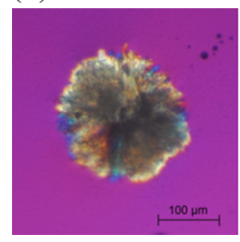

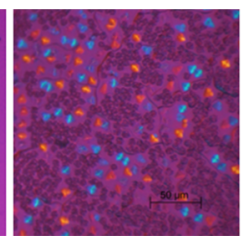

(b)

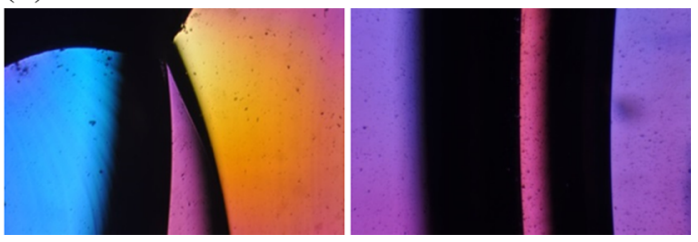

Fig. 1 a Examples of the crystallization on the surface of glass sample, $\mathbf{b}$ and stress induced by the thermal expansion difference (polariscope images)

Crystallization susceptibility can be investigated by three methods: differential scanning calorimetry (DSC), diffractive X-ray measurements (XRD) or by isothermal heating method. In this work we used the third method, which is simple and sufficient for our purposes, considering that the aim of our work was to avoid the crystallization in developed glasses. Characterization of the observed crystals formed in some of the samples was not intended to study. The glass sample with polished surface was heated for $2 \mathrm{~h}$ at the sphere creation temperature, determined in Leitz heat microscope, that corresponds to glass viscosity $\eta=$ $10^{6} \mathrm{P}$, and then after cooling the sample surface was inspected for presence of crystals using a microscope with attached polariscope. When the surface is changed or the crystals are visible, the glass has tendency to crystallization. The distribution and sizes of grown crystals can be compared with a composition changes in glass series, leading to design thermally stable glass. The examples of crystals grown on the glass surface appeared after isothermal heating test are shown in Fig. 1. Such a picture was observed only for glasses with clear tendency to crystallization. Lack of crystals testifies about high thermal stability of glass. The last test before choosing pair of glasses for joint thermal processing was the "sandwich" test. One polished glass plate was placed between two plates cast from different type of glass. Such stack is heated to the sphere creation temperature and slowly cooled. After cooling, this "sandwich" structure is cut and polished, and inspected under a polariscope. The observed difference between the colors of sample enables to identify stress induced by the difference in the thermal expansion during cooling. Images of prepared "sandwich" samples are shown on Fig. 1. Measured properties of melted glasses are summarized in Table 2.

In order to fabricate a stable optical structure comprising two jointly thermal-processed glasses, the difference in linear thermal coefficient has to be minimized, and viscosity of each of the glasses has to be matched. Excessive difference in linear thermal coefficient introduces stress at the interface of the two materials and results in cracking during cooling, especially in components of larger dimensions. From our experience the thermal expansion difference for two joined glasses should not exceed $10 \%$, which means about $8 \times 10^{-7} \mathrm{~K}^{-1}$ in our case, to maintain stable structures. In this work we select glasses for joint process of fiber drawing. The optimal viscosity ( $\log \eta$ ) for drawing process is between 7.6 and 8 . For optimal selection of two glasses, their viscosities had to be in this range at the same temperature for stable process. Additionally, glasses should not crystallize; this will prevent multi-thermal processing like stack-and-draw method. Stack-and-draw involves typically between two and four consecutives steps of stacking of glass preform elements and drawing them at a fiber drawing tower. In this procedure, drawing of stacked elements is the thermal processing step. Considering glass parameters like viscosity, characteristic temperatures and crystallization resistance, the best candidate for joint thermal processing with lead-silicate glasses is our glass labelled NC-21A. The chosen glass does not have barium oxide in composition and is characterized by high thermal stability. This glass passed crystallization test without observable crystals on the surface of the thermally treated sample. Properties of the glasses chosen 
Table 2 Basic thermal and optical properties of the investigated high-alkaline borosilicate glasses

\begin{tabular}{|c|c|c|c|c|c|}
\hline Parameter & NC-17 & NC-18 & NC-19 & NC-20 & $\mathrm{NC}-21 \mathrm{~A}$ \\
\hline $\begin{array}{r}\text { Refractive } \\
\text { index } n_{d}\end{array}$ & 1.5422 & 1.5385 & 1.5360 & 1.5292 & 1.5275 \\
\hline $\begin{array}{l}\text { Linear thermal } \\
\text { expansion } \\
\text { coefficient } \\
\text { for the range of } 20- \\
250^{\circ} \mathrm{C} \alpha\left[10^{-7} \mathrm{~K}^{-1}\right]\end{array}$ & 83.0 & 83.2 & 83.4 & 85.0 & 86.0 \\
\hline $\begin{array}{l}\text { Transformation } \\
\text { temperature } \\
\mathrm{T}_{\mathrm{g}}\left[{ }^{\circ} \mathrm{C}\right] \log \eta=13.4\end{array}$ & 508 & 505 & 506 & 492 & 492 \\
\hline $\begin{array}{l}\text { Dilatometric softening } \\
\text { point DTM } \\
{\left[{ }^{\circ} \mathrm{C}\right] \log \eta=11.0}\end{array}$ & 550 & 549 & 554 & 538 & 542 \\
\hline \multicolumn{6}{|c|}{ Characteristic temperatures determined in Leitz heating microscope $\left[{ }^{\circ} \mathrm{C}\right]$} \\
\hline $\begin{array}{l}\text { Oval of the sample } \\
\mathrm{T}_{\mathrm{Z}} \log \eta=9.0\end{array}$ & 600 & 590 & 600 & 575 & 600 \\
\hline $\begin{array}{l}\text { Sphere creation } \\
\mathrm{T}_{\mathrm{k}} \log \eta=6.0\end{array}$ & 695 & 690 & 690 & 680 & 680 \\
\hline $\begin{array}{l}\text { Hemisphere creation } \\
\mathrm{T}_{\mathrm{pk}} \log \eta=4.0\end{array}$ & 760 & 755 & 750 & 740 & 720 \\
\hline $\begin{array}{l}\text { Spread of the sample } \\
\mathrm{T}_{\mathrm{r}} \log \eta=2.0\end{array}$ & 920 & 930 & 940 & 920 & 860 \\
\hline $\begin{array}{l}\text { Crystallization test } \\
\text { (heating in sphere } \\
\text { creation temperature } \\
\text { for } 2 \mathrm{~h} \text { ) }\end{array}$ & $\begin{array}{l}\text { Clearly seen } \\
\text { crystallization }\end{array}$ & $\begin{array}{l}\text { Traces of } \\
\text { crystallization }\end{array}$ & $\begin{array}{l}\text { Traces of } \\
\text { crystallization }\end{array}$ & $\begin{array}{l}\text { Single crystals } \\
\text { present }\end{array}$ & $\begin{array}{l}\text { Lack of } \\
\text { crystals }\end{array}$ \\
\hline
\end{tabular}

Table 3 Properties comparison of F2, SF6 glass (Schott), and NC-21A (ITME)

\begin{tabular}{|c|c|c|c|}
\hline \multirow{2}{*}{$\frac{\text { Parameter }}{\text { Refractive index } n_{d}}$} & \multicolumn{2}{|c|}{ NC-21AF2 } & \multirow{2}{*}{$\frac{\mathrm{SF6}}{1.805}$} \\
\hline & 1.526 & 1.620 & \\
\hline $\begin{array}{l}\text { Linear thermal expansion coefficient for the } \\
\text { range of } 20-250{ }^{\circ} \mathrm{C} \alpha\left[10^{-7} \mathrm{~K}^{-1}\right]\end{array}$ & 87.2 & 91.9 & 90.3 \\
\hline $\begin{array}{l}\text { Lower annealing temperature } \\
\quad \mathrm{t}_{d}\left[{ }^{\circ} \mathrm{C}\right] \log \eta=14.6\end{array}$ & 462 & 400 & 405 \\
\hline $\begin{array}{l}\text { Transformation temperature } \\
\qquad \mathrm{T}_{g}\left[{ }^{\circ} \mathrm{C}\right] \log \eta=13.4\end{array}$ & 487 & 431 & 442 \\
\hline $\begin{array}{l}\text { Upper annealing temperature } \\
\mathrm{t}_{g}\left[{ }^{\circ} \mathrm{C}\right] \log \eta=13\end{array}$ & 496 & 440 & 450 \\
\hline $\begin{array}{l}\text { Dilatometric softening point DTM } \\
{\left[{ }^{\circ} \mathrm{C}\right] \log \eta=11.0}\end{array}$ & 527 & 480 & 463 \\
\hline \multicolumn{4}{|c|}{ Characteristic temperatures determined in Leitz heating microscope $\left[{ }^{\circ} \mathrm{C}\right.$} \\
\hline Oval of the sample $T_{z} \log \eta=9.0$ & 580 & 520 & 520 \\
\hline Sphere creation $\mathrm{T}_{\mathrm{k}} \quad \log \eta=6.0$ & 670 & 620 & 600 \\
\hline Hemisphere creation $\mathrm{T}_{\mathrm{pk}} \log \eta=4.0$ & 740 & 820 & 665 \\
\hline Spread of the sample $T_{r} \log \eta=2.0$ & 860 & 1,130 & 880 \\
\hline
\end{tabular}

for further processing are summarized in Table 3. The viscosity-temperature relationship is presented in Fig. 2.

Group refractive index $N$ was measured by the white light interferometric technique in the $400-1,700 \mathrm{~nm}$ range, and phase refractive index $n$ for sodium line was measured with an Abbe 


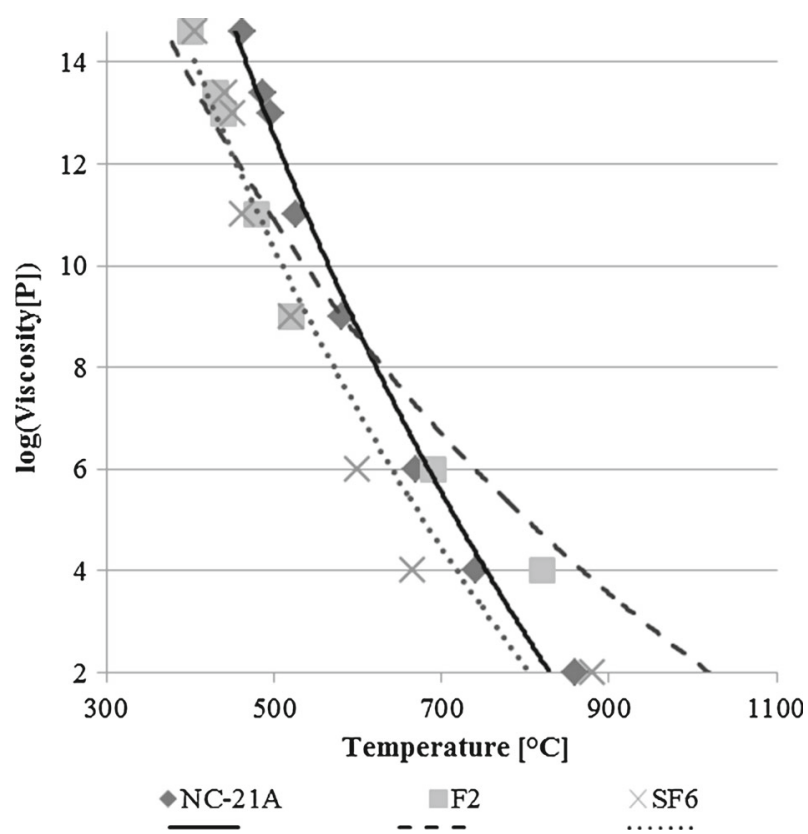

Fig. 2 Viscosity-Temperature relationship for tested glasses

refractometer. To obtain dispersion of the refractive index, classic Michelson interferometer setup was used (Fig. 3a). The cubic sample of the examined glass was placed in the signal arm of interferometer. The reference arm was equipped with a mirror mounted on the linear, manual stage, that enabled to measure the optical path difference (OPD) introduced by the glass in the signal arm. The interference patterns, as shown in Fig. 3b, was observed and analyzed by means of the spectrometers for visible and near infrared range. Measurement of the OPD as a function of the equalization wavelength allowed to determine the spectral dependence of group refractive index. Obtained curve was fitted by the function, that describes dispersion of group index of refraction $N(\lambda)$ by including Sellmeier coefficients:

$$
N(\lambda)=n(\lambda)+\frac{\lambda^{2}}{n(\lambda)} \cdot \sum_{i=1}^{3} \frac{B_{i} C_{i}}{\left(\lambda^{2}-C_{i}\right)^{2}}
$$

where phase index of refraction $n(\lambda)$ is given by the Sellmeier formula:

$$
n(\lambda)=\sqrt{1+\sum_{i=1}^{3} \frac{B_{i} \lambda^{2}}{\lambda^{2}-C_{i}}}
$$

The Sellmeier coefficients for NC-21A glass were: $\mathrm{B}_{1}-1.15702228, \mathrm{~B}_{2}-0.14959764, \mathrm{~B}_{3}-$ $1.36007514, \mathrm{C}_{1}-0.00614152, \mathrm{C}_{2}-0.02521981, \mathrm{C}_{3}-122.8441325$. Measurements of glass transmittance were performed with the VARIAN Cary 500 spectrophotometer in the range of 200-3,300 nm; results are presented in Fig. 4. 

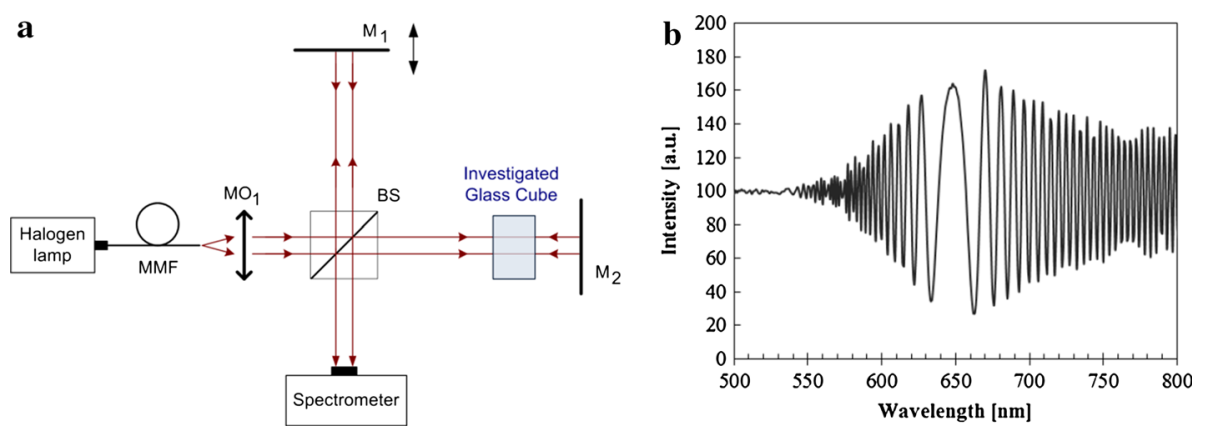

Fig. 3 a Setup of the Michelson interferometer used for measurements, b signal from the spectrometer (interference fringes)
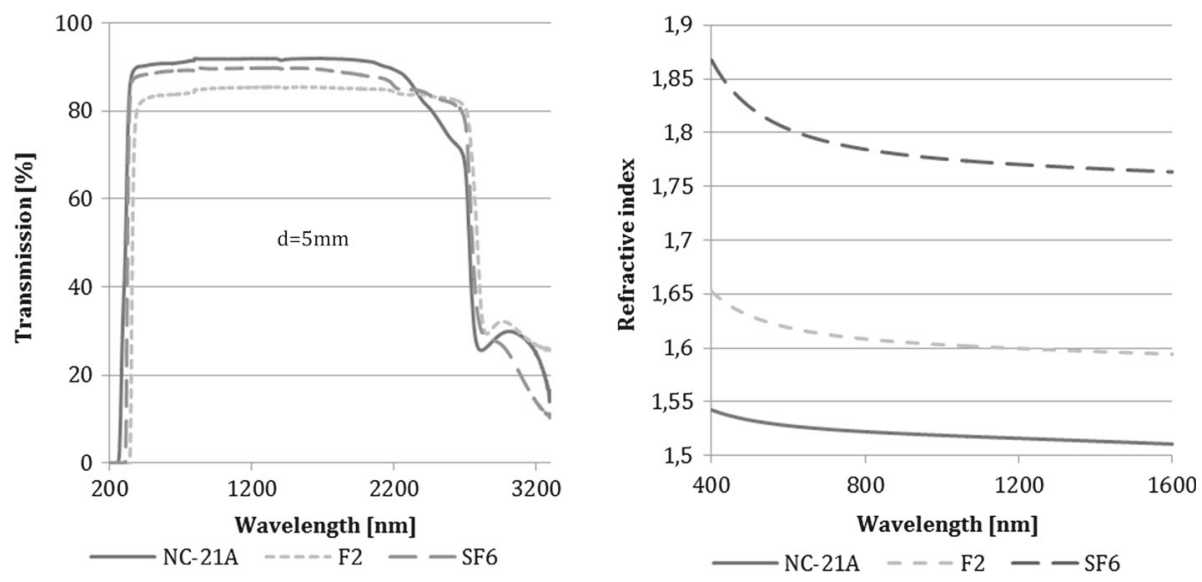

Fig. 4 Transmission (left) and the group refractive index (right) of the selected glasses, NC-21A borosilicate glass (ITME)—solid line, F2 and SF6 (Schott)_dotted and dashed line respectively. Thickness of glass samples was $5 \mathrm{~mm}$

\section{Fiber development with thermally matched glasses}

Final result confirming the possibility to join two glasses into stable material is fabrication of microstructured optical fiber. From the investigated glasses we choose glass designated NC21A, which has the most favorable viscosity, thermal expansion and crystallization resistance properties for joint thermal fiber drawing. The fibers were made by the stack and draw method.

The photonic structure of the fiber labelled NL21, made of F2 and NC-21A glasses, was designed using numerical methods. The initial parameters of the fiber were: lattice constant $(\Lambda)=1.8 \mu \mathrm{m}$, and linear filling factor $\geq 0.9$. The structure had a hexagonal lattice with 15 elements on diagonal, with a solid core made of F2 glass in the center. The fluctuations of the air pressure inside the air holes were eliminated by replacing them with glass rods.

Second pair of glasses, SF6 and NC-21A, were used to fabricate photonic crystal fiber (NL22) with lattice composed of 7 rings of air holes with solid core made of NC-21A, with a nano-inclusion of SF6 glass. This defect in the core was added to investigate influence of the nanostructure in the core on the dispersion of the fiber. It allows shifting dispersion characteristic of fundamental mode without changing mode area and mode properties (Pniewski et 

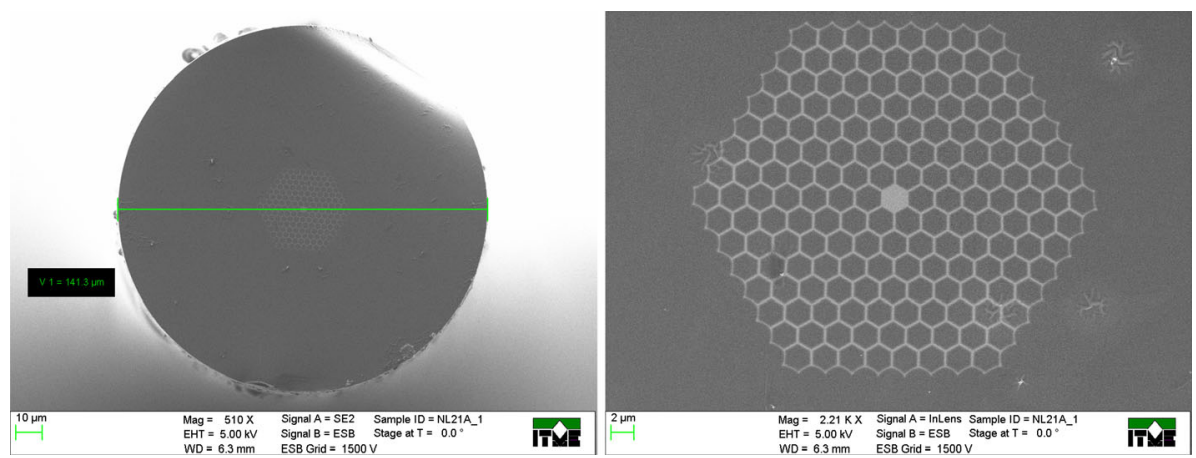

Fig. 5 NL21 fiber made of NC21A glass, with F2 glass as a PCF lattice and core (brighter color)
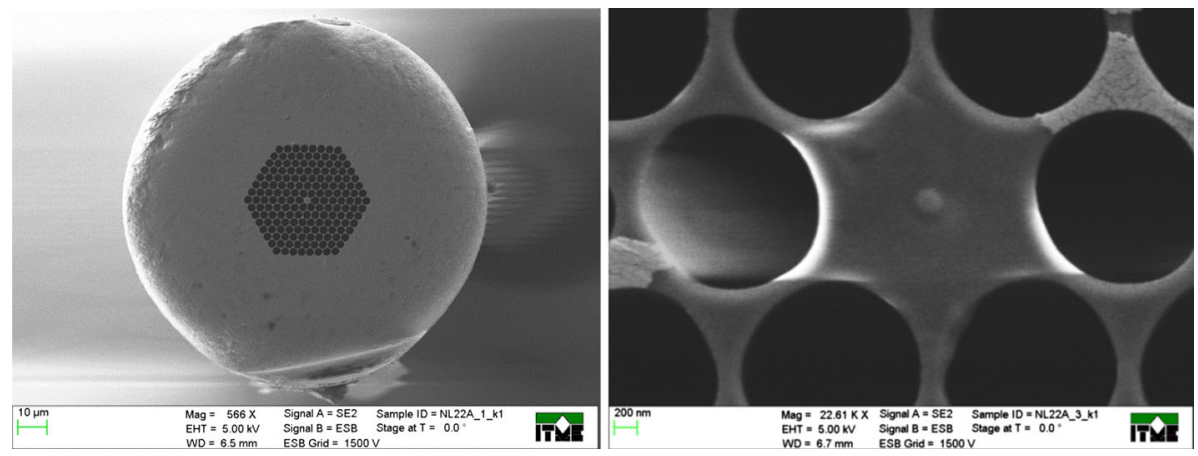

Fig. 6 Fiber made of NC-21A, with a nano-inclusion in the core of SF6 glass (seen as brighter round element at the center of the core)

al. 2012). The initial parameters were: lattice constant $(\Lambda)=2.8 \mu \mathrm{m}$, and linear filling factor $\geq 0.9$. The outer diameters of both fibers were $125 \pm 2 \mu \mathrm{m}$. SEM images of fabricated fibers are shown in Fig. 5 and in Fig. 6. The brighter colors correspond to the Schott lead-silicate glasses.

\section{Conclusions}

This work demonstrates the possibility of joint thermal processing of commercially available lead-silicate glass with high-alkaline borosilicate glass after optimization of its composition. Presented pairs of glasses F2-NC-21A and SF6-NC-21A were successfully synthesized for stacking and drawing of all-solid photonic crystal fibers. Difference in thermal expansion coefficients of the two glasses at a level of $4.2 \times 10^{-7} \mathrm{~K}^{-1}$ enabled fabrication of mechanically stable, all-solid photonic crystal fibers. The refractive index contrasts between our NC-21A borosilicate glass and the F2 or SF6 glass were 0.094 and 0.279 respectively. Further work in this area will include optimization of borosilicate glass for thermal processing with our compositions of highly nonlinear glasses (Lorenc et al. 2008) and maintaining a refractive index difference larger than 0.4 .

The all-solid photonic crystal fibers composed of two glasses enable e.g. engineering of dispersion profiles flattened over several hundred nanometers, which can find application 
in the pulse compression and supercontinuum generation. Further works on this type of fibers shall enable achieving refractive index contrast comparable to that in classic photonic crystal fibers made of fused silica with air holes. Additionally, application of two glasses allows creating subwavelength structures with unique properties (Nowosielski et al. 2012). An additional advantage will be experimental investigation of joining two glasses with different spectral transmission ranges.

Acknowledgments This work was supported by the project TEAM/2012-9/1 operated within the Foundation for Polish Science Team Programme co-financed by the European Regional Development Fund, Operational Program Innovative Economy 2007-2013.

Open Access This article is distributed under the terms of the Creative Commons Attribution License which permits any use, distribution, and reproduction in any medium, provided the original author(s) and the source are credited.

\section{References}

Bouwmans, G., Bigot, L., Quiquempois, Y., Lopez, F., Provino, L., Douay, M.: Fabrication and characterization of an all-solid 2D photonic bandgap fiber with a low-loss region $(<20 \mathrm{~dB} / \mathrm{km})$ around $1550 \mathrm{~nm}$. Opt. Express 13(21), 8452-8459 (2005)

Buczynski, R., Pniewski, J., Pysz, D., Stepien, R., Kasztelanic, R., Kujawa, I., Filipkowski, A., Waddie, A.J., Taghizadeh, M.R.: Dispersion management in soft glass all-solid photonic crystal fibres. Opto-electron. Rev. 20(3), 207-215 (2012)

Feng, X., Monro, T.M., Petropoulos, P., Finazzi, V., Hewak, D.: Solid microstructured optical fiber. Opt. Express 11(18), 2225-2230 (2003)

Gu, B., Yuan, W., Zhang, A.P., Bang, O.: All-solid birefringent hybrid photonic crystal fiber based interferometric sensor for measurement of strain and temperature. In: Proceedings SPIE $8311 \mathrm{~m} 831121$ (2011)

Jin, L., Wang, Z., Liu, Y., Kai, G., Dong, X.: Ultraviolet-inscribed long period gratings in all-solid photonic bandgap fibers. Opt. Express 16(25), 21119-21131 (2008)

Lorenc, D., Aranyosiova, M., Buczynski, R., Stepien, R., Bugar, I., Vincze, A., Velic, D.: Nonlinear refractive index of multicomponent glasses designed for fabrication of photonic crystal fibers. Appl. Phys. B 93, 531-538 (2008)

Nowosielski, J., Buczynski, R., Waddie, A.J., Filipkowski, A., Pysz, D., McCarthy, A., Stepien, R., Taghizadeh, M.R.: Large diameter nanostructured gradient index lens. Opt. Express 20(11), 11767-11777 (2012)

Olausson, C.B., Falk, C.I., Lyngsø, J.K., Jensen, B.B., Therkildsen, K.T., Thomsen, J.W., Hansen, K.P., Bjarklev, A., Broeng, J.: Amplification and ASE suppression in a polarization-maintaining ytterbium-doped all-solid. Opt. Express 16(18), 13657-13662 (2008)

Pniewski, J., Pysz, D., Stepien, R., Kujawa, I., Waddie, A.J., Taghizadeh, M.R., Buczynski, R.: Dispersion properties of all-solid photonic crystal fibers with nanostructured core. In: Proceedings SPIE 8426, Microstructured and Specialty Optical Fibres, 84261J (2012). doi:10.1117/12.922699

Pniewski, J., Kasztelanic, R., Pysz, D., Stępień, R., Buczyński, R.: Supercontinuum generation in all-solid photonic crystal fibers with a low index subwavelength inclusion in the core. Laser Phys. 23(8), 085104 (2013)

Stępień, R., Pysz, D., Kujawa, I., Buczyński, R.: Development of silicate and germanate glasses based on lead, bismuth and gallium oxides for midIR microstructured fibers and microoptical elements". Opt. Mater. 35(8), 1587-1594 (2013)

Toupin, P., Brilland, L., Renversez, G., Troles, J.: All-solid all-chalcogenide microstructured optical fiber. Opt. Express 21(12), 14643-14648 (2013)

Waddie, A.J., Buczynski, R., Hudelist, F., Nowosielski, J., Pysz, D., Stępień, R., Taghizadeh, M.R.: Form birefringence in nanostructured micro-optical devices. Opt. Mater. Express 1(7), 1251-1261 (2011) 